EESTI NSV TEADUSTE AKADEEMIA TOIMETISED. VII KÖIDE

BIOLOOGILINE SEERIA. 1958, NR. 2

ИЗВЕСТИЯ АКАДЕМИИ НАУК ЭСТОНСКОИ ССР. ТОМ VII

СЕРИЯ БИОЛОГИЧЕСКАЯ. 1958, № 2

\title{
ROSA AFZELIANA FRIES JA ROSA CANINA L. ROOSIDE POOKEALUSTENA
}

\author{
V. VESKI
}

Roosid on väga vanad kultuurtaimed. Nende kultiveerimine ulatub arvatavasti aega, mil tekkisid esimesed pōllumajanduskolded Aasia mägedes, nagu Pamiiris, Tiibetis ja Iraanis.

Edaspidises roosikasvatuses kujunesid tsentrumid juba sekundaarsetes põllumajanduskultuurikolletes, kus vastastikune suhtlemine tekkis karavani- ja laevateede kaudu. Tähtsamateks roosikasvatuse keskusteks peetakse Hiinat ja Iraani. Viimasest kandus rooside kultiveerimine kreeklaste ja roomlaste kaudu Euroopasse. Keskajal jäi roosikasvatus soiku, kuid keskaja lôpu poole ja renessansiajal elavnes ta uuesti. Kuni XVIII sajandini olid tuntud niisugused aiaroosid, mis ōitsesid ainult üks kord suve jooksul. Alles pärast seda, kui hakati kasutama roosisortide aretusel $R$. chinensis Jacq., saadi pidevalt õitsvaid roosisorte. Tänapäeval ulatub rooside sortiment mitmekümne tuhandeni. Sordid on kujult, vormilt, värvuselt ja aroomilt väga erinevad, kuid selle mitmekesise sortimendi lähtekomponentideks on olnud ainult kaheksa roosiliiki: R. centifolia L., $R$. gallica L., $R$. damascena Mill., $R$. moschata Herrm., $R$. chinensis Jacq., $R$. multiflora Thunb., $R$. foetida Herrm. ja $R$. Wichuraiana Crép.

Roosid oma mitmekesise värviskaala, vormirikkuse ja hea aroomiga pakuvad suurepäraseid kasutamisvõimalusi nii haljastamisel, koduümbruse kaunistamisel kui ka ruumide dekoreerimisel.

Kultuurroosid ei anna oma väärtuslikke omadusi edasi seemnetega; pealegi ei valmi nende seemned meie oludes. Sellepärast paljundatakse neid vegetatiivselt - okuleerimise vōi pookimise teel. Sel juhul koosneb roos kahest komponendist - maapealsest kultuurosast ja maasisesest pookealuse juurtest.

Eesti NSV kliima on kultuurrooside jaoks karm. Külmad talved ja üleliigne niiskus talvkatte all vōivad neid hävitada. Pookealusega saab aga kultuurrooside talvekindlust môjutada. Sellepärast on pookealuse valik väga șuure tähtsusega. Kostetski $\left.{ }^{5}\right]$ soovitab kasutada roosialuseks neid kibuvitsaliike, mis on teatavas paikkonnas rohkesti levinud ja kohanenud sealse keskkonna tingimustega. Alljärgnevalt vaatlemegi, milline Eesti NSV-s levinud kibuvitsadest sobib meie klimaatilistes tingimustes kultuurroosi aluseks.

Kohalikud kibuvitsad on kasvanud samades keskkonnatingimustes aastatuhandeid, mille tagajärjel nende elutegevus on vastavalt kohanenud ning välja kujunenud. Neid liike ei hävita vastavas paikkonnas esinevad erakorralised looduslikud tingimused (pakased ja niisked talved, pōuased suved jne.).

Spontaansetest kibuvitsaliikidest on Eesti NSV-s levinud peamiselt sektsiooni Caninae esindajad: $R$. canina L. (koer-kibuvits), $R$. ajzeliana Fries ( $R$. glauca Vill. - harilik kibuvits), $R$. coriifolia Fries (nahklehine kibuvits), $R$. eglanteria L. ( $R$. rubiginosa L. näärmekas kibuvits) ja $R$. mollis $\mathrm{Sm}$. (pehme kibuvits), kuna sektsioonist Cinnamomeae esineb ainult üks liik, nimelt $R$. cinnamomea L. (mets-kibuvits). Kõige ulatuslikuma levikuga (176 leiukohaga) on $R$. afzeliana Fries; sellele järgneb (89 leiukohaga) $R$. cinnamomea L. Mōlemad liigid on levinud kogu Eesti territooriumil, viimane harvemini kui esimene. Nad on kõige paremini kohanenud meie vabariigi klimaatiliste tingimustega. Isegi erakordselt pakastel talvedel $(1939 / 40,1955 / 56)$ ei kannatanud nad nimetamisväärselt. Mullastikutingimuste suhtes vōib öelda sama: mõlemad on kohanenud kõigi Eesti NSV-s esinevate muldadega. $R$. afzeliana kasvab veelgi kuivematel ja kehvematel muldadel kui $R$. cinnamomea, saavutades vōrdlemisi hea kasvu. Esimene liik kasvab harilikult lagedamatel kohtadel, teine aga enam metsades ja vōsastikes. Nii on $R$. afzeliana harjunud rohkema, $R$. cinnamomea vähema valgusega. Sellest järgneb, et kumbki liik on erinevat assimilatsioonitüüpi.

Kultuurroosid vajavad rohkem valgust; varjus ōitsevad nad halvasti. Seega tuleks valgusnōudlikkust silmas pidades eelistada pookealusena $R$. afzeliana't, mis assimilatsioonitüübilt sobib paremini kultuurroosidega. 
Kirjanduse andmetest $[2,3,15,18]$ selgub, et $R$. cinnamomea'le vääristatud kultuurroosid on lühikese elueaga ja ajavad palju juurevõrseid, mis tōendab kultuurosa poolt valmistatud assimilaatide sobimatust. Need asjaolud piiravad $R$. cinnamomea laialdasemat kasutamist pookealusena.

Sektsiooni Caninae teised liigid on Eesti NSV-s levinud alljärgnevalt.

$R$. canina $\mathrm{L}$. on esindatud 23 ja $R$. mollis $\mathrm{Sm}, 27$ leiukohaga lääneranniku ja saarte floora valdkonnas; $R$. eglanteria L. -7 leiukohaga samas valdkonnas, kahe leiukohaga põhjaranniku ja paekalda alavaldkonnas ning ühe leiukohaga Kagu-Eesti valdkonnas; $R$. coriifolia Fries - 44 leiukohaga lääneranniku ja saarte floora valdkonnas ning 13 leiukohaga pōhjaranniku ja paekalda alavaldkonnas. Siit nähtub, et kōik nimetatud liigid on levinud Eesti NSV-s kitsal territoriaalsel alal ja piiratud hulgal. Läänerannikul ja saartel on talved tavaliselt soojemad kui mandri keskosas, kuid pakastel talvedel esineb sealgi külmakahjustusi.

$R$. canina L. kasutatakse pookealusena Nôukogude Liidus, Kesk-Euroopas ja PõhjaAmeerikas. Teda on üksmeelselt soovitanud paljud autorid $\left[{ }^{1-4}, e_{-13},{ }^{15-18}\right]$. See tõendab, et $R$. canina on paremaid aluseid. Eesti NSV pakastel talvedel külmab ta tagasi [14]. Tartu Riikliku Olikooli (TRU) Botaanikaaias korraldatud vaatluse pōhjal hakkasid $R$. canina lehed roostehaiguse (Phragmidium subcortitium) tōttu varisema septembri algul. Kirjanduses leidub andmeid ka $R$. eglanteria ja $R$. mollis'e kasutamise kohta pookealustena, kuid neid eriti ei soovitata. TRU Botaanikaaias korraldatud vaatluste pōhjal hakkasid nende lehed roostehaiguse tagajärjel varisema juba augusti lõpul vôi septembri algul. $R$. mollis on ka ebajahukaste vastu tundlik.

Introdutseeritud Rosa-liikidel, mida kirjanduse andmeil kasutatakse pookealusteks, on negatiivseid omadusi, mis takistavad nende laiemat kasutamist. R. rugosa'l (kurdlehine roos) on kultuursort lühiealine $\left[10,11,15 \_17\right]$; $1939 / 40$. a. talvel külmus ta tagasi kuni maapinnani [14]. R. glauca Pourr. ( $R$. rubrifolia Vill. - punalehine roos) on roostehaigusele vastuvōtlik ning ei taha mitmete sortidega kokku kasvada $\left[{ }^{2}, 6\right] ; 1939 / 40$. a. talvel külmus ta tagasi ${ }^{[14}$; roostehaiguse tôttu hakkasid ta lehed TRO Botaanikaaias varisema juba augusti lōpul. R. multif́lora Thunb. (paljuōieline roos) on aga Eesti NSV avamaatingimustes pookealusena külmatundlik [14]. Ka Moskva oludes külmavad tema juured pakastel talvedel, kuid pookeosa võib osaliselt säilida $\left[{ }^{2}\right.$ ]. Kordese $\left.{ }^{10}\right]$ järgi on $R$. multiflora Saksamaal heaks pookealuseks vään- ja polüantroosidele, kuna teehübriidid, pernetja remontantroosid hakkasid sellel alusel hääbuma, jättes roosipõllule suured tühikud.

Seega osutub kirjanduse andmeil parimaks aluseks $R$. canina.

Kultuurroosidel on sugulussidemeid subtroopiliste roosidega. Külmakindlamatest rooside sektsioonidest Caninae, Cinnamomeae ja Pimpinellifoliae on kōige suuremas suguluses subtroopiliste roosidega sektsioon Caninae, kuhu kuulub ka $R$. canina. Caninae-sektsioonist tuleks sobivamaid pookealuseid otsida ka fülogeneetiliste andmete põhjal, mis lasevad oletada, et nimetatud sektsioonis on meie tingimustes teisigi roosialuseks sobivaid liike, kuigi nende kohta puuduvad andmed. Neil kaalutlustel rajati TRU Botaanikaaias võrdluskatsed pookealustega $R$. canina L. ja $R$. afzeliana Fries, millele vääristatî mitmesuguseid kultuursorte.

\section{Katsemetoodika}

Katsealal TRU Botaanikaaias oli nōrgalt leelisene saviliivmuld. Rooside pookealuste jaoks koguti seemneid TRU Botaanikaaiast ( $R$. canina L.) ja Harju rajoonist Lehmja tammiku lähedalt tee äärest ( $R$. afzeliana Fries). Selleks et jälgida rooside kasvamist ja arenemist erinevatel aastatel, istutati pookealused kohale 1950., 1951. ja 1953. a. kevadel. Istutamiseks valiti ca $0,5 \mathrm{~cm}$-lise juurekaela läbimōōduga alused, mille jaoks kaevati $30 \mathrm{~cm}$ laiune ja $40 \mathrm{~cm}$ sügavune kraav. Sinna paigutati nad ritta $35 \mathrm{~cm}$-liste vahedega, kusjuures ridade vahet jäeti $80 \mathrm{~cm}$. Istutati nii sügavale, et juurekaela ülemine osa oli maapinnaga ühel tasemel, ja vajutati kõvasti kinni; pärast seda kasteti. Read suunati kagust loodesse. Iga põôsa kohta koguti andmeid ja kanti need märkmikku.

Esialgne materjal okuleerimistööde läbiviimiseks saadi Moskvast NSV Liidu Teaduste Akadeemia Peabotaanikaaiast, ENSV TA Taimekasvatuse Instituudi (praegu Eesti Maaviljeluse ja Maaparanduse Teadusliku Uurimise Instituut) Polli filiaalist, Tallinna Bioloogia Eksperimentaalbaasist (praegu ENSV TA Eksperimentaalbioloogia Instituut) ja mitmelt vabariigi rooside kollektsionäärilt. Viimastel aastatel hakati saama okuleerimismaterjali ka juba omalt katsealalt. Okuleerimist teostati igal aastal augustikuu esimesel dekaadil. Okuleerimistehnika oli tavaline: silm ühes kilbikesega pandi juurekaelale tehtud T-kujulisse lôikesse, seoti raffiaga ja mullati kohe. $3-4$ nädala pärast vabastati juurekael mullast ja kontrolliti pungade kokkukasvamist pookealusega (kokkukasvanud pungad olid rohelised, kuna hävinud pungad olid muutunud mustaks). Sügisel mullati pookealused ca $10 \mathrm{~cm}$ kõrguseni ja kaeti sõnnikuga. Kevadel pärast lume sulamist vabastati juurekael kattest ja kontrolliti pungade talvitumist. Aprilli lõpul vôi mai algul lōigati 
metsik osa kuni kultuurpunga kilbi ülemise ääreni tagasi, Igal kevadel aprillikuus anti väetuseks $250 \mathrm{~kg}$ pro ha kaalisoola ja $400 \mathrm{~kg}$ pro ha superfosfaati ning mai lōpul $300 \mathrm{~kg}$ pro ha ammooniumsalpeetrit. Suve jooksul seisnesid hooldamistööd umbrohu hävitamises ja mulla kohendamises. Kahjurite tōrjeks kasutati anabasiinsulfaati.

TRU Botaanikaaias okuleeritud kultuursortide külgekasvamist alustele jälgiti aastatel 1950-1953. Põõsalt lōigatud õite hulk on tähtsaks kriteeriumiks, mis annab ülevaate pōõsa tootlikkuse kohta. Selle näitaja alusel saab võrrelda erinevail alustel kasvatatud sama sordi põōsaid. Seda silmas pidades jälgiti kogu katseperioodi vältel erilise hoolega õite hulka ja vegetatiivset kasvu. Teehübriidide ja remontantrooside sortidel lōigati pooleldi avanenud õied ära ühes võrsetega.

Ka taime vegetatiivne kasv on kriteeriumiks, mis vöimaldab otsustada erinevatel pookealustel kasvanud ühe ning sama sordi tugevuse üle. Igal sügisel vegetatsiooniperioodi lōpul mōōdeti sentimeetrites iga roosipōōsa võrsete pikkused, millele liideti suve jooksul lõigatud õite võrsete pikkused. Nii saadi iga põõsa üldine vegetatiivne kasv. Nende andmete omavaheline vōrdlemine vōimaldas hinnata vastavaid aluseid.

Katsealal lasti osa $3-4$ aasta vanuseid roosipōõsaid vabalt kasvada, ilma et neilt oleks õisi lõigatud vōi neid pintseeritud. Sellise katse eesmärgiks oli kindlaks teha, kui palju õisi roosipõõsastel suve jooksul ōitseb, missugusele ajale langeb ōitsemine, kui kaua see kestab ja kas on selles suhtes märgata erinevusi pookealuste vahel. Vastavad katsesordid valiti suuremalt osalt polüanthübriidide rühmast, kuid võeti ka teehübriidide ja remontantrühma esindajaid. Oite arv loendati iga viie päeva tagant, nimelt 5. , 10.. 15., 20., 25. ja 30. kuupäeval. Märgitud päevadel loendati nii õitsevad kui ka õitsenud õied. Polüantrühma sortidel teatavasti õitseb korraga palju õisi; samuti lōpetab ôitsemise terve rida ōisi korraga. Et viimased ei segaks ôite loendamist järgmisel viispäevakul, murti nad ära.

Teostati anatoomilisi uuringuid pookealuse ja kultuurosa kokkukasvamise kohta aastavanuste teehübriidide, remontantrooside ja polüanthübriidide rühma kuuluvate sorti dega, mis olid okuleeritud pookealustele $R$. canina L. ja $R$. afzeliana Fries. Pookealuse ja kultuurosa kokkukasvamise kohalt tehti mikroskoopilisi lōikeid mitmest erinevast kohast - nii puit- kui ka niinosast. Puitosa eraldamiseks kasutati floroglutsiini- ja soolhappemenetlust ning säilitustärklise kindlakstegemiseks joodi proovi. Igast uuritavast sordist tehti üks püsipreparaat ning mikroloto nii väikesel $(120 \times)$ kui ka suurel $(600 \times)$ suurendusel.

Kuna tugevama juurestikuga pōõsad on ka ise tugevamad ning lopsakamad, vaadeldi ka sellega seoses olevaid momente - juurestiku tugevust, hargnevust ja külgjuurte rohkust. 1954. a. vegetatsiooniperioodi lõpul kaevati sügavalt välja teehübriidide, remontantrooside ja polüanthübriidide rühma sortide esindajaid (igast sordist 3 pōõsast). Kuigi väljakaevamisel polnud võimalik kõiki juuri kogupikkuses kätte saada, andsid nad siiski teatava üldpildi. Kuna sordi piirides esines juurestiku tugevuses erinevusi, valiti keskmise juurestikuga pōōsas. Väljakaevatud põōsad fotografeeriti.

\section{Okuleerimise tulemused}

Pookealus võib tõsta poogendi külmakindlust, haigustele vastupidavust ja kultuursordi talvekindlust. Sellepärast annabki erinevate roosiliikide kasutamine pookealustena erinevaid tulemusi. Eespool toodud andmetest selgub, et $R$. afzeliana on Eesti NSV oludes külmakindlam ja kohaneb muude klimaatiliste tingimustega paremini kui $R$. canina. Neil kaalutlustel uuriti ning võrreldi pookealustele $R$. afzeliana ja $R$. canina okuleeritud kultuursortide pungade külgekasvamist ja nende talvitumist.

Eespool kirjeldatud metoodika põhjal teostatud okuleerimiskatsed näitasid, et pookealusele $R$. canina okuleeritud kultuurroosisordid kasvasid alusega üldiselt veidi paremini kokku kui samad sordid pookealusel $R$. afzeliana. Talvitumisel aga hukkus pookealusele külgekasvanud kultuursortide pungi $R$. canina'l sedavõrd rohkem, et kasvama läinud pungade protsent oli $R$. afzeliana'1 märgatavalt suurem. Seda esines teehübriidi, remontantroosi ja polüanthübriidi rühmade juures, kuna roniroosidel oli kasvama läinud pungade protsent mõlemal alusel peaaegu võrdne. Niisiis pidasid $R$. afzeliana'le okuleeritud pungad Eesti NSV niisketel ja külmadel talvedel paremini vastu kui $R$. canina'le okuleeritud pungad.

$R$. afzeliana'le ja $R$. canina'le okuleeriti teehübriidide ja pernetrooside 
rühma 36 sorti - esimesele pookealusele 186, teisele 171 punga samadest sortidest. Okuleerimistulemuste kontrollimisel 3-4 nädala pänast selgus, et $R$. afzeliana'l oli ilusaid pungi $165(88,7 \%)$ ja $R$. canina'l $162(94,7 \%)$. Teised okuleeritud silmad ei olnud alustega kokku kasvanud, vaid olid muutunud mustaks ning hävinud. Võrreldes esitatud andmeid ilmnes, et $R$. canina'l oli okuleeritud pungade ja pookealuse kokkukasvamisprotsent 6 võrra suurem kui $R$. afzeliana'l! Kevadel läks $R$. afzeliana'le okuleeritud pungadest kasvama $128(68,8 \%)$ ja $R$. canina'le okuleeritud pungadest 109 $(63,7 \%)$, seega $5,1 \%$ võrra vähem.

Polüianthübriidi rühma üheksal sordil oli $R$. canina'le külgekasvanud pungade protsent sügisel 5 võrra suurem. Järgmisel kevadel aga, vastupidi, läks $R$. afzeliana'l kasvama $27,1 \%$ rohkem pungi kui $R$. canina'l.

Remontantrühma kolmel sordil oli $R$. canina'le okuleeritud pungadest sügisel alusega kokku kasvanud $1,2 \%$ rohkem pungi, võrreldes $R$. afzeliana'ga. Kevadel ilmnes aga vastupidine nähtus: $R$. afzeliana'l läks kasvama $19,9 \%$ rohkem pungi kui $R$. canina'l.

Ronirooside neljal sordil oli $R$. afzeliana'le poogituna kasvama läinud pungade protsent kevadel 5,2 võrra suurem kui $R$. canina'le pookimise puhul.

Need andmed rõhutavad küllalt ilmekalt $R$. canina eeliseid pookealusena. Temale okuleeritud pungad kasvavad külge võrdlemisi hästi. Nagu näitavad katsed, hukkub neid aga talvitamisel $R$. afzeliana'le okuleeritud pungadest rohkem. Seepärast saab $R$. afzeliana'le okuleeritud pungadest suurema protsendi kultuurroose kui $R$. canina'le okuleeritud pungadest.

\section{Oite hulga, vegetatiivse kasvu, juurestiku tugevuse ja anatoomilise urimise tulemusi alustel $R$. afzeliana ja $R$. canina}

Tähtsaks kriteeriumiks pookealuse väärtuse hindamisel on roosipõõsialt lõigatud õite hulk ja kogu põõsa vegetatiivne kasv, s. o. võrsete kogupikkus sentimeetrites. Katseteks valiti teehübriidide rühma sortidest enamasti «Hadley» ja «Etoile de Hollande» ning veel 19 sorti. Lõigatud õite hulk oli teehübriidide rühma sortide ühe kuni nelja aasta vanustel põõsastel pookealusel $R$. afzeliana keskmiselt 6,9 ja pookealusel $R$. canina 4,6. Nelja aasta keskmine vegetatiivne kasv põõsa kohta oli $R$. afzeliana'l $370 \mathrm{~cm}$ ja $R$. canina'l $252 \mathrm{~cm}$.

Poolroniroosi sordil «New-Dawn» oli nelja aasta keskmine õite arv põõsa kohta $R$. afzeliana'le poogitult 10,9 ja $R$. canina'le poogitult 6,5 . Vegetatiivne kasv nelja aasta jooksul oli põ̃õsa kohta $R$. afzeliana'l keskmiselt $1073 \mathrm{~cm}$ ja $R$. canina'l $626 \mathrm{~cm}$.

Remontantrooside rühma sordid («Frau Karl Druschki», «Ulrich Brunner») andsid $R$. afzeliana'l kolme aasta jooksul keskmiselt 6,7 öit, $R$. canina'l 4,8 õit. Vegetatiivne kasv samal ajavahemikul oli $R$. afzeliana'] $598 \mathrm{~cm}$ ja $R$. canina'l $525 \mathrm{~cm}$.

Polüanthübriidi sordi «Orange Triumph» $3-5$ aasta vanustel roosipõõsastel õitsenud kolme aasta keskmine õite hulk oli pookealusel $R$. canina 194 , pookealusel $R$. afzeliana aga 237, seega 43 õit rohkem (joon. 1).

Protsentuaalsed andmed õite hulga varieerumise kohta eri roosipõõsastel näitavad, et kuni kolme õiega põõsaid on rohkem pookealusel $R$. canina, kuna nelja ja enama õiega põõsaste poolest on edukam $R$. afzeliana.

Anatoomilised uuringud näitasid, et sordi «Etoile de Hollande» liitumiskohal eespool nimetatud pookealustega esines kohati kitsaid kalluseribasid, mis «Ulrich Brunner'il» täiesti ja «Hadley'l» peaaegu puudusid. «NewDawn'il» ei esinenud kalluseribakest liitumisel $R$. afzeliana'ga, kuid 


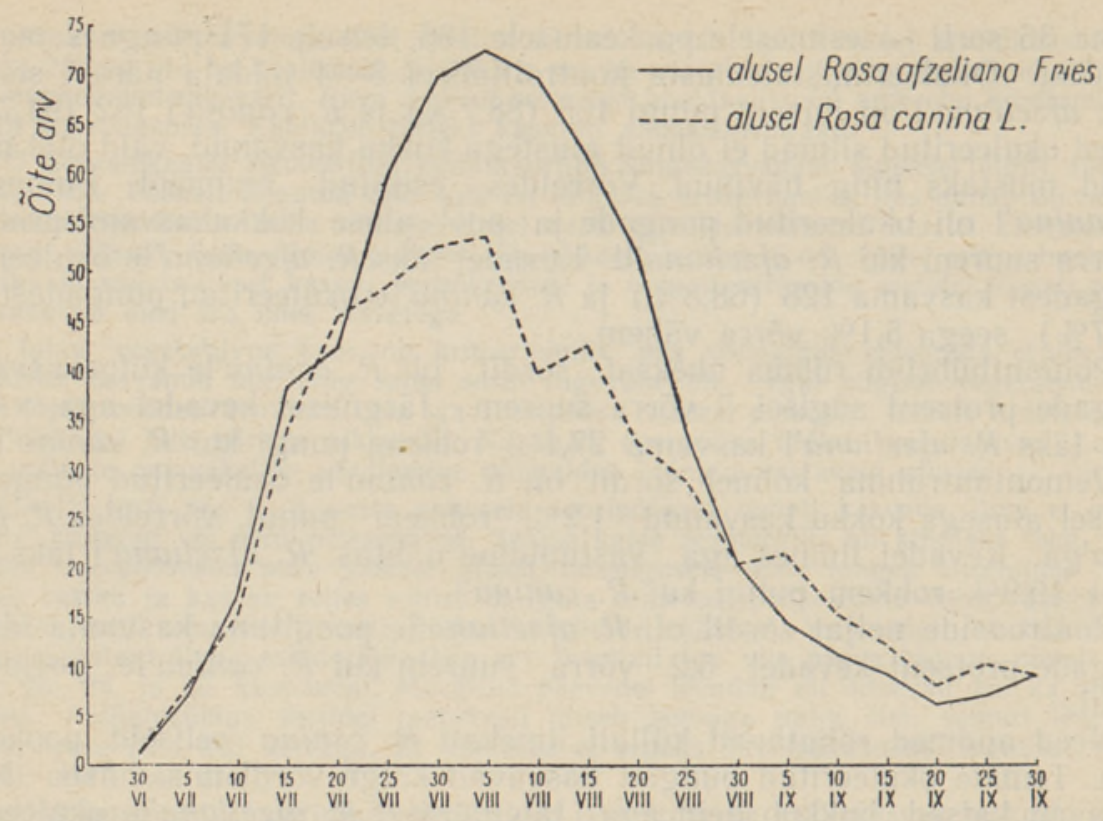

Joon. 1. Roosisordi «Orange Triumph» õitsvate õite hulk viispäevakutel (1953.-1955. a. keskmised andmed).

$R$. canina'ga liitumise kohal oli see paiguti nähtav. See oligi üheks põhjuseks, miks $R$. canina'l kasvanud üheaastastelt põõsastelt saadi õisi kolm korda vähem kui $R$. afzeliana'l kasvanud põõsastelt. «Orange Triumph'il» esines pookealustega ühinemise kohal kalluseriba. Eriti lai oli see $R$. canina puhul, püsides kitsamal kujul veel teiselgi aastal. Muude sortide puhul kalluseriba teisel aastal enam ei esinenud, vaid ta oli asendunud püsikoega. Osalt selle tõttu oligi teisel aastal sordi «Orange Triumph» vegetatiivne kasv pookealusel $R$. canina poole väiksem kui pookealusel $R$. afzeliana. Püsikoe rakkude tekkimist vốis jälgida «Orange Triumph'il», kusjuures võis nende hulgas märgata trahheiide.

Võrreldes roosipõõsaste juurestiku tugevust kõnesolevail pookealustel ilmnes, et kõige suuremad erinevused selles suhtes olid «New-Dawn'il». Sellel sordil oli $R$. afzeliana'le poogituna palju tugevam ja hargnenum juurestik kui kasvades alusel $R$. canina. Sellepärast oli ka õite hulk temal suurem kui teistel sortidel. Ka sordid «Orange Triumph», «Frau Karl Druschki» ja «Hadley» olid pookealusel $R$. afzeliana juurestiku poolest tugevamad kui $R$. canina'l kasvanult.

1957. aastal tehti kokkuvõtteid rooside talvitamise kohta kõnesolevail pookealustel. Katseaja (7 aasta) jooksul oli väga erinevaid talvi; seega olid ka rooside talvitamistingimused olnud erinevad, Järgnevalt vaadeldaksegi rooside talvitamist kahel karakteersel talvel, 1955/56. ja 1956/57. aastal.

Mõlemal talvel olid roosid kaetud ühtlaselt. Mullakatte peale pandi sügisel kestvate külmade saabumisel kuuseoksi, mis omakorda kaeti puulehtedega.

1956. a. jaanuarikuu III dekaadil ja veebruari I dekaadil langes õhutemperatuur kuni $-35^{\circ} \mathrm{C}$-ni. Sel talvel hävis katseala roosidest $R$. canina'l $15 \%$ ja $R$. afzeliana'l $14 \%$. 
1957. a. jaanuarikuu III dekaadil ja veebruarikuu I dekaadil oli sula: keskmine temperatuur 20 päeva jooksul oli $0^{\circ}$. Sel talvel hävis roose $R$. afzeliana'l $12 \%$ ja $R$. canina' $128 \%$, peamiselt just liigniiskuse tagajärjel.

Vaadeldes $R$. canina'l hävinud roose rühmade kaupa ilmneb, et kõige rohkem hävis neid teehübriidide rühmast, kuna remontantroosid säilisid kõik. See näitab, et teehübriidid on talvitamisel eriti tundlikud liigniiskuse suhtes. Samal niiskel talvel oli laga teehübriidide hukkumine $R$. afzeliana'l palju väiksem kui $R$. canina'l.

Võrreldes 1955/56. la. ja 1956/57. a. rooside talvekahjustusi pookealustel $R$. afzeliana ja $R$. canina nähtub, et $R$. afzeliana'l talvitanud roosidel suuri erinevusi hukkunute protsendis ei esinenud. Kuid $R$. canina'l hukkus 1956/57. a. talvel $13 \%$ roose rohkem kui 1955/56. a. talvel. Sellest nähtub, et niisketel talvedel talvitasid roosid pookealusel $R$. canina palju halvemini kui pookealusel $R$. afzeliana. Seega osutub ka talvitamise suhtes $R$. afzeliana paremaks aluseks kui $R$. canina.

Esitatud andmetest selgub, et Eesti NSV klimaatilistes tingimustes on Rosa afzeliana Fries rooside pookealuseks sobivam kui Rosa canina L. Esimesele okuleeritud kultuurroosipungad talvitasid hästi ja temal kasvavad roosid ületasid õite hulga ning vegetatiivse kasvu poolest teisel alusel kasvanud samavanused roosid. Uldiselt oli ka $R$. afzeliana'l kasvanud roosisortide juurestik tugevam. Anatoomilised uuringud tōendasid rooside kultuurosa head kokkukasvamist pookealusega $R$. afzeliana. $R$. afzeliana paljundamiseks pole seemnete hankimine raske. Neid saab koguda looduslikult kasvavatelt põõsastelt, mida leidub eriti rikkalikult rannikualadel.

\section{KIRJANDUS}

1. Д е с я то в Г., Роза. Петербург, 1912.

2. Иже в ски й С. А., Розы. Москва, 1949.

3. Кичунов Н. И., Культура роз в открытом грунте и под стеклом. Петербург, 1895.

4. К и ч ун о в Н. И., Розы. Ленинград, 1929.

5. К о с т ец и й И. Н., Разведение роз. Симферополь, 1951.

6. Ми ч ур ин И. В., Сочинения III. Сельхозгиз. Москва, 1948.

7. С а а ко в С. Т., Деревья и кустарники СССР, т. III. Москва, 1954, lk. 685.

8. Ш те йн берг П. И., Грунтовая культура розы. Петербург, 1907.

9. B o n stedt, C., Parey's Blumengärtnerei, I. Berlin, 1931, lk. 766.

10. Kordes, W., Rosen. Frankfurt-Berlin, 1932.

11. Kordes, W., Das Rosenbuch. Hannover, 1956.

12. Kr ü ssma n n, G., Die Vermehrung der Gehölze. Berlin, 1935, 1k. 103-105.

13. K r ü s s m a n n, G., Die Laubgehölze. Berlin, 1951, lk. 311.

14. M a thiesen, A., Külmakahjustustest puudel ja põōsastel 1939.-1940. a. talvel. Tartu, 1940, lk. 19.

15. Olbrich, S., Der Rose Zucht und Pflege. Berlin, 1925.

16. R a thlef, H., Die Rose und ihre Kultur. Ludwigsberg, 1940.

17. R athlef, H., Rosen der Deutschen Hindukuschekspedition 1935. Die Gartenbauwissenschait 1941, Nr. 16, lk. 1.

18. Th o m a e, K., Rosenkultur und Rosenschulbetrieb. Berlin, 1928.

Eesti NSV Teaduste Akadeemia

Eksperimentaalbioloogia Instituut
Saabus toimetusse 28. XI 1957 


\title{
ROSA AFZELIANA FRIES И ROSA CANINA L. В КАЧЕСТВЕ ПОДВОЕВ РОЗ
}

\author{
В. Ю. Вески
}

\section{Резюме}

Важнейшим способом размножения культурных роз является окулировка, в связи с чем встает проблема подвоев роз.

Нами были окулированы разные сорта роз на подвоях $R$. canina и $R$. afzeliana c тем, чтобы проследить на указанных подвоях срастание сортов, обилие цветения, вегетативный рост и развитие корневой системы.

Из групп чайногибридных и пернецианских роз были окулированы 37 сортов. На $R$. afzeliana окулировались 186 и на $R$. canina 171 глазок этих сортов. Проверка результатов окулировки, произведенная через 3-4 недели после прививки, показала, что y $R$. afzeliana хорошо срастающихся глазков было $88,7 \%$ и у $R$. canina $94,7 \%$. Таким образом, $R$. canina дала срастания на $6 \%$ больше, чем $R$. afzeliana. Весной из окулированных на $R$. afzeliana глазков стали расти $68,8 \%$, а из окулированных на $R$. canina глазков - $63,7 \%$, т. е. на $5,1 \%$ меньше.

На основе опытов по окулировке 17 сортов из группы полиантовых гибридов, ре. монтантных и плетистых роз выяснилось, что у $R$. afzeliana из 301 глазка осенью срослось хорошо $89 \%$, из них перезимовало хорошо $72 \%$; y $R$. canina из 271 глазка срослось осенью $93 \%$, а хорошо перезнмовало только $62 \%$, т. е. на $10 \%$ меньше, чем у R. afzeliana.

Из приведенных данных следует, что срастание глазков привоя на подвое $R$. canina на $4-5 \%$ больше, а количество хорошо перезимовавших глазков на $10 \%$ больше у $R$. afzeliana.

Из вышесказанного видно, что $R$. canina лучше срастается с глазками окулированных культурных сортов, чем $R$. afzeliana. Однако при перезимовке на подвое $R$. canina погибает столько глазков культурных роз, что процент выросших глазков у $R$. afzeliana значительно выше. Поэтому из глазков, окулированных на R. afzeliana, получается больший процент культурных роз, чем из глазков, окулированных на $R$. canina.

Важным критерием для оценки подвоя является количество роз, полученных с одного куста, а также весь вегетативный рост. $R$. afzeliana имеет в ЭССР более широкое распространение, чем $R$. canina; поэтому можно предполагать, что она лучше приспособлена к нашим условиям. Результаты прививок на 740 кустах показали, что количество цветов и вегетативный рост сортов чайных гибридов, ремонтантных и плетистых роз, привитых на $R$. afzeliana, значительно больше, чем у тех же самых сортов, привитых на $R$. canina. Подопытными сортами из группы гибридов чайных роз были главным образом «Эдель», «Этуаль де Олланд» и дополнительно еще 18 сортов. Среднее количество цветов, полученных у 20 сортов из группы чайных гибридов, составляло на подвое $R$. afzeliana 6,9 и на подвое $R$. canina 4,6 . Bегетативный рост у сортов той же группы был на подвое $R$. afzeliana $370 \mathrm{~cm}$, а на подвое $R$. canina 252 см.

У полуплетистого сорта «Нью-Даун» количество цветов на подвое $R$. afzeliana было 10,9 , а на $R$. canina 6,5 . Вегетатнвный рост на подвое $R$. afzeliana составлял 1073 см, на $R$. canina - 626 cм. Сорта ремонтантных роз («Фрау Қарл Друшки», «.Ульрнк Бруннер») дали на подвое $R$. afzeliana в течение 3 лет в среднем 6,7 цветов, на $R$. canina 4,8 цветов. Вегетативный рост за это время был на подвое $R$. afzeliana $598 \mathrm{~cm}$, а на $R$. canina 525 см. Данные о варьировании количества цветов у молодых чайногибридных роз показали, что кустов с количеством до 3 цветков имеется больше на подвое $R$. canina, тогда как кустов с количеством до 4 и больше цветков встречается больше на подвое $R$. afzeliana.

Среднее количество цветов 3-5-летних кустарников у полиантогибридног сорта «Оранж-Триумф» было на подвое $R$. canina 194, на подвое $R$. afzeliana 237, следовательно, на подвое $R$. afzeliana было на 43 цветка больше. Среднее количество цветов в течение 3 лет показано на рис. 1 .

Сравнивая мощность корневой системы кустов на подвоях $R$. canina и $R$. afzeliana, мы установили, что различия в корневой системе самые большие у сорта «Нью-Даун». Этот сорт имеет на подвое $R$. afzeliana значительно сильнее развитую и разветвленную корневую систему, чем на подвое $R$. canina. Сорта «Оранж-Триумф», «Фрау Карл Друшки» и «Эдель» также имеют на подвое $R$. afzeliana более сильную корневую систему, чем на подвое $R$. canina. 


\section{ROSA AFZELIANA FRIES UND ROSA CANINA L. ALS ROSENUNTERLAGEN}

\section{W. Weski}

\section{Zusammenfassung}

Versuche mit verschiedenen Rosensorten, auigezogen auf den Unterlagen $R$. canina L. und $R$. afzeliana Fries ( $R$. glauca Vill.), ergaben, dass bei der ersten Unterlage die Zahl der Augen um 4-5\% grösser war als bei der zweiten. Bei der zweiten Unterlage dagegen war die Zahl der Augen, die gut überwintert hatten, um $10 \%$ grösser. Bei der $R$. canina als Unterlage wuchsen also die Augen der Kultursorten etwas ergiebiger als bei $\operatorname{der} R$. afzeliana; trotzdem fanden sich bei der letzteren im Frühling mehr gut erhaltene Augen.

Von den auf der $R$. afzeliana okulierten 21 Bastardsorten der Teerose wurden im Laufe von vier Jahren im Durchschnitt 6,9 Blüten gesammelt. Bei der $R$. canina war die entsprechende Zahl bloss 4,6. Der vegetative Zuwachs war in derselben Zeit bei der $R$. afzeliana $370 \mathrm{~cm}$, bei der $R$. canina $252 \mathrm{~cm}$.

Die Halbkletterrose «New-Dawn» als Edeling auf der $R$. afzeliana als Unterlage, gab im Laufe von vier Jahren durchschnittlich 10,9 Blüten, auf der $R$. canina aber 6,5; dabei war der vegetative Zuwachs entsprechend $1073 \mathrm{~cm}$ und $626 \mathrm{~cm}$.

Sorten der Remontantrose («Frau Karl Druschki», «Ulrich Brunner») gaben auf der $R$. afzeliana durchschnittlich 6,7 Blüten, auf der $R$. canina 4,8 ; ihr vegetativer Zuwachs war $698 \mathrm{~cm}$ bzw. $525 \mathrm{~cm}$.

3-5 Jahre alte Stöcke einer Bastardsorte der Polyanthrose «Orange Triumph» gaben im Laufe von drei Jahren aui der $R$. canina als Unterlage durchschnittlich 194, auf der R. afzeliana aber 237 Blüten (Fig. 1).

Ein Vergleich der respektiven Stärke des Wurzelwerks der Unterlagen $R$. canina und $R$. afzeliana ergab die grössten Abweichungen bei der Veredelung mit der «New-Dawn». Mit der $R$. afzeliana als Unterlage erlangte diese Sorte viel kräftigere und besser verzweigte Wurzeln als mit der $R$. canina. Demgemäss war auch ihre Blütenzahl grösser als bei den anderen Sorten.

Anatomische Untersuchungen zeugten gleichfalls von einer ungemein guten Verwachsung der Edelinge mit der $R$. afzeliana als Unterlage.

Institut für Experimentalbiologie
der Akademie der Wissenschaften
der Estnischen SSR
Eingegangen am 28. Nov. 1957 